\title{
NEGATIVE INVERSION IN STANDARD ENGLISH
}

\author{
Lucía Muñoz Martín, University of Burgos ${ }^{1}$ \\ Email: lucilumm@hotmail.com
}

Received: June 10, 2020

Accepted: October 27, 2020

\begin{abstract}
This paper takes a descriptive approach to several properties of Negative Inversion (NI) in Standard English found controversial in prescriptive writings, comparing what has been previously written in the literature with real native English speakers' grammaticality judgements gathered via a questionnaire. These topics include the disagreement on the optionality of subject-auxiliary (subj-aux) inversion, the different approaches to an accurate syntax analysis, whether NI behaves as a Root Phenomenon (RT) or not, and the inaccurate classification of Only Inversion as a subtype of NI.
\end{abstract}

Keywords: Negative inversion, English syntax, non-canonical syntax phenomena, negative adverbials, subject-auxiliary inversion.

Resumen: Este artículo toma un enfoque descriptivo con respecto a las propiedades controversiales de la Inversión Negativa (NI) en inglés estándar encontradas en previos escritos prescriptivos, comparándolos con los juicios gramaticales de hablantes nativos a través de una encuesta. Estas cuestiones incluyen el desacuerdo sobre la opcionalidad de inversión de sujeto-verbo, la cuestión de si NI se comporta como un Root Phenomenon (RT) o no, los distintos análisis sintácticos propuestos para el fenómeno y la imprecisa consideración de la inversión de Only como un subtipo de NI.

Palabras clave: Inversión negativa, sintaxis inglesa, fenómeno sintáctico no-canónico, adverbios negativos, inversión de sujeto-verbo.

\section{INTRODUCTION}

The present paper deals with controversial topics within Negative Inversion (NI) in Standard English, which have arguably not yet been given a completely satisfactory explanation, such as the optionality of subject-auxiliary (subj-aux) inversion when there is a preposed negative element, whether NI behaves as a Root Phenomenon (RT) or not, and the classification of Only Inversion as a subtype of NI.

1 This paper is based on the author's dissertation, written in 2018 and available at addi, the digital archive of the University of the Basque Country (UPV/EHU). 
Negative Inversion (NI) is a non-canonical syntax phenomenon in which a negative constituent appears in a non-canonical position in the left periphery of the sentence triggering subject-auxiliary inversion (1).

(1) a. Never have I ever been abroad (Google).

b. Under no condition would I leave this town.

c. John swore that under no circumstances would he accept their offer (Authier 1992: 331).

d. Where did Mary say that never again would she go? (Radford 2009: 333).

e. Only then did he realize that he had made a terrible mistake (Francis 2017: 214).

It can affect both adjuncts (2) and arguments (3).

(2) a. On no account could she move to Paris (De Clercq 2010: 1).

b. Not until December can we go to see grandma (adjuncts).

(3) a. None of those would he want to eat (Büring 2004: 1).

b. Not a sound could we hear (complements) (Google).

A prominent property of NI is that, like in root yes/no questions (5) and wh- questions (6), it, in most cases, obligatorily triggers subject auxiliary inversion (4.b-c), which is not the case in other non-canonical syntax phenomena like Topicalization (Top) (7) or Focus Preposing (FP) (8).

(4) a. I have never seen such a big lion.

b. Never have I seen such a big lion.

c. *Never I have seen such a big lion.

(5) a. Will Bill go to the movies? (yes/no question).

b. *Bill will go to the movies?

(6) a. When will you go? (wh-question).

b. *When you will go?

(7) a. Muffins, I will eat tomorrow (Topicalization).

b. *Muffins, will I eat tomorrow. 
(8) a. MACADAMIA NUTS I will eat. (Focus Preposing)

b. *MACADAMIA NUTS will I eat.

Another property that NI (9) and wh-questions (10) have in common is that they, unlike Topicalization (11), do not tolerate an intonational phrase break (or comma intonation, indicated by the symbol ",") between the fronted constituent and the rest of the sentence (Haegeman 2000; Büring 2004).

(9) a. Nowhere does he mention my book.

b. *Nowhere, does he mention my book (NI).

(10) a. When will you go? (wh-question).

b. *When, will you go?

(11) Somewhere, he mentions my book (Topicalization) (Büring 2004: 3).

It is important to make a distinction between NI and Topicalized negative constituents (12). NI (12.a) has scope over the whole sentence, which is thus negative. So (12.a) can be paraphrased by Mary would not be happy even if she had the best job. While Top (12.b) has scope over the constituent it accompanies, and can be paraphrased by Mary would be happy if she did not have a job (Haegeman 2000).

(12) a. With no job would Mary be happy (NI).

b. With no job, Mary would be happy (Top).

Unmistakable evidence that NI sentences are negative and Topicalization of negative elements are positive comes from some tests (13-15), which are: neither/so-tag-test (13), adding I don't think to the sentence (14) and tag questions (15) (Haegeman 2000). If a sentence is negative, it should be able to appear featuring neither, I don't think and the tag question would, which is the case with all the sentences below, which are NI. The opposite happens when the sentence is positive, then, we can see that all the b sentences, which are Top, are positive because they are ungrammatical whenever we add neither, I don't think or would.

(13) a. With no job would Mary be happy, and neither/*so would Jane.

b. With no job, Mary would be happy, and *neither/so would Jane.

(14) a. With no job would Mary be happy, I don't think.

b. With no job, Mary would be happy, *I don't think. 
(15) a. With no job would Mary be happy, would/*wouldn't she?

b. With no job, Mary would be happy, *would/wouldn't she?

Another significant difference between NI and Top is that NI is focal in nature, while Top is topical, i.e. NI introduces new information, thus being able to appear as an answer to a yes-no question (16) (Maekawa 2007).

(16) a. Did you see anyone?

b. No, not a single person did I see (Culicover 2013: 247).

This paper will only cover NI, therefore it will not focus on Topicalized negative constituents.

Next, I will consider another characteristic of NI, which is a topic of some discussion in the literature, which is whether NI is a bounded or unbounded operation. Some scholars (Collins and Postal 2014, Radford 2009, Sobin 2003) believe NI to be a bounded operation, i.e. NI can only move to the left periphery of the clause where it is base-generated (17). In (17.a) and (17.b) we can see a parallelism, in both sentences the preposed negative constituent never again moves to the left periphery of the clause where it has been base-generated. In (17.a) never again is giving information about the constituent eat clams, thus meaning Mary will eat clams never again; while in (17.b) never again accompanies the verb say, thus meaning I never again said that. On the other hand, (17.c) is not grammatical because not a penny is modifying the verb bring (Mary remembered to bring not a penny) which appears in the clause where the negative constituent has been generated; however, not a penny appears outside such clause, in the matrix clause.

(17) a. I said [that never again $i$ will Mary eat clams $t i]$.

b. [Never again $i$ did I say $t i]$ that Mary will eat clams.

c. *Not a penny $i$ did Bill say [that Mary remembered to bring $t i$ ] (Adapted from Sobin 2003: 184-185).

However, this is not the behaviour one would expect because, typically, most preposed elements which move to the left periphery of a sentence in phenomena such as Top, FP, or wh-questions are unbounded and can move long distance, i.e. are able to move to a left peripheral position inside the clause they have been base-generated in (18.a), or to a left peripheral position outside such clause, in the matrix clause (18.b).

a. I asked [whati Bill said ti].

b. Whati did Bill say [that Mary remembered to bring $t i$ ]? (Adapted from Sobin 2003: 185).

Furthermore, if we take into account that NI is focal in nature, as we have seen in (16), one would expect it to also be an unbounded operation like FP but, as it is exemplified in (17.c), this does not seem to be the case. Nevertheless, it looks like NI unbounded extraction 
is acceptable for some native English speakers as well (19) (Maekawa 2007). In (19) the preposed negative constituent never again refers to the constituent eat clams (she will eat clams never again), not to the main verb in the matrix clause think, which normally is not grammatical, as we saw in (17.c).

(19) Never again $i$ do I think [that she will eat clams ti] (Adapted from Maekawa 2007: 194).

Further research would be needed as to explain why certain long-distance movements of NI are ungrammatical (17.c) and why others are accepted by some (19), and in what contexts can each appear.

\section{MOST DEBATED ISSUES WITHIN NI.}

\subsection{Optionality of Inversion}

Notice that in the introduction it was noted that NI in most cases requires subj-aux inversion (4) -repeated below-. Although its description is not homogeneous.

(4) a. I have never seen such a big lion.

b. Never have I seen such a big lion.

c. *Never I have seen such a big lion.

As we can see in (20), when the negative constituent Not until the next morning, which is an adjunct, is preposed, the sentence without inversion is ungrammatical (20.a), while the inverted counterpart is grammatical (20.b). Whereas, as we can see in (21), when the negative constituent None of them, which is a complement, is preposed, both sentences (21.a) without inversion and (21.b) with inversion are grammatical.

(20) a. *Not until the next morning she realised how serious it was.

b. Not until the next morning did she realise how serious it was (Adapted from Büring 2004: 3).

(21) a. None of them he found useful.

b. None of them did he find useful (Adapted from Büring 2004: 1).

Haegeman (2000) claims that inversion is always compulsory, considering the grammaticality of negative preposed elements without inversion as an elliptic form in informal speech. Sentence (22.a) appears without inversion because it is the elliptic form of (22.b).

(22) a. Nothing I have seen that could rival the pyramids.

b. [There is] nothing I have seen that could rival the pyramids (Adapted from Haegeman 2000: 26, footnote 5). 
Cormark and Smith (2000), however, consider both (23.a), with inversion, and (23.b), without inversion, equally grammatical sentences.

(23) a. Nothing did I eat for breakfast.

b. Nothing I ate for breakfast (Cormark and Smith 2000: 402).

They give an explanation for this fact, as they claim that there are two fronting mechanisms: Фon and Gap structures. Фon is the semantic head which morphologically selects for the PF-interpretable part of some sign (i.e. word class, number, gender...), and Gap is a Case assigner. For them, the inverted structure (23.a) is derived by the use of Gap, and the non-inverted structure (23.b), by Фon.

Some scholars such as Büring (2004) state that inversion is optional in some cases. The explanation is that negative preposed elements which are adjuncts obligatorily trigger subject-auxiliary inversion (20), whereas inversion with negative preposed complements is optional (21) even though examples of NI with complements (21.b) are rare.

To conclude which is the best explanation, it would be interesting to see how native English speakers who are not familiar with this issue behave in this respect. In section 3 I will give the results obtained from carrying out a survey on this topic.

\subsection{NI as a Root Phenomenon}

Emonds (1964) proposes that there are two main classes of transformations: structure preserving transformations and root transformations (RT). Structure preserving transformations are operations in which certain constituents move to positions in which they might have been generated. An example of a structure preserving transformation is Passivation (24.a), in which a DP object is moved to spec of IP, a position where DPs can be generated (24.b).

(24) a. Peteri was killed $t i$.

b. Mary killed Peter.

On the other hand, RTs or Non-Structure preserving transformations are operations in which certain constituents move to positions in which they could not be generated. An example of a RT is Topicalization (Top) (25.a), in which a DP is moved to the left periphery of the clause, a position where it would not be generated (25.b).

(25) a. Billi, I don't know ti.

b. That boyi, I don't like $t i$.

Structure preserving transformations are possible in root clauses (24.a), i.e. a main clause which is not embedded; embedded root clauses (25.a), i.e. subordinate clauses which behave as root clauses, for example in embedded clauses as the complement of that clauses introduced by verbs of saying (Class A) as say, report, exclaim..., verbs which describe mental processes (Class B) as suppose, believe, think... and by semi-factive verbs, i.e. verbs 
which describe the way in which the speaker knows something to be true (Class E) realize, learn, find out...; and embedded non-root clauses, (42.b) i.e. subordinate clauses which do not behave as root clauses, for instance in complement position of that clauses introduced by verbs which do not assert propositions (Class C) as doubt, deny... nor with verbs which describe feelings (Class D) as resent, regret, bother... Whereas RTs are restricted to root clauses (26.a) and a subset of root-like subordinate clauses, but cannot appear in embedded non-root clauses (27.b) as Hooper and Thomson (1973: 474-481) argue.

(26) a. I think [that Peteri was killed $t i]$ (Embedded root clause).

b. [If Peteri is killed $t i]$ we will have to go away (Embedded non-root clause).

(27) a. I think [that Billi, she doesn't know ti] (Embedded root clause).

b. *[If Billi she doesn't know $t i]$ I won't invite him (Embedded non-root clause).

Following this distinction, then, both Emonds (1964) and Hooper and Thomson (1973) consider NI to be a Root Transformation phenomenon because it behaves as phenomena like Top.

(28) a. Not a single book did he buy (Root clause).

(29) b. I exclaimed that never in my life had I seen such a crowd (Embedded root clause, Class A verb) (Hooper and Thomson 1973: 474).

c. I believed that never would our promise be broken. (Embedded root clause, Class B verb) (Google).

d. I found out that never before had he had to borrow money (Embedded root clause, Class E verb).

(30) d. *It's likely that seldom did he drive that car (Embedded root clause Class C verb).

e. *He was surprised that never in my life had I seen a hippopotamus (Embedded root clause, Class D verb).

c. *The proof that at none of the beaches are the lifeguards alert is that there have been many fatalities (Embedded non-root clause) (Emonds 1964: 15).

More evidence for considering NI a RT comes from the fact that NI is possible in nonrestrictive relative clauses (NR) (31.a) which are known to behave as root clauses, but are not possible in restrictive relative clauses, as they do not behave as root clauses (31.b).

(31) a. This car, [which only rarely did I drive], is in excellent condition (NR).

b. *The car that only rarely did I drive is in excellent condition (Restrictive Relative Clause) (Adapted from Hooper and Thompson 1973: 489). 
Also, NI cannot appear within noun phrases (NPs) which have as their head a noun of saying (32.a), nor in reduced clauses i.e. as complement of a clause with an uninflected verb (32.b), neither in idioms as stop at nothing (33) and think nothing (34). It cannot appear in expressions which impose indefinite interpretations on DPs (35), nor in predicative expressions (36) (Hooper and Thomson 1973).

(32) a. *Your notion that never before have the children had so much fun is absurd.

(33) b. *The director wanted [on no account to accept that solution] (Infinitive clause).

(33) a. *Nothing will Carla stop at to get that job.

b. Carla will stop at nothing to get that job.

(34) a. Vernon thinks nothing of drinking nine beers.

b. *Nothing does Vernon think of drinking nine beers.

(35) a. There is no (is not any) gorilla in that SUV.

b. *No gorilla is there in that SUV.

(36) a. Boris will be no Einstein/will not be any Einstein.

b. *No Einstein will Boris be (Hooper and Thomson 1973: 485-286).

Emonds (1964) considers sentences featuring NI within preposed if clauses, which behave as embedded non-root clauses, to be ungrammatical (37), as we saw in (27.b), it was also the case in Top sentences.

(37) *If under no conditions may they leave the area, how can they pay their debt (Emonds 1964: 15).

(27) b. *[If Billi she doesn't know ti] I won’t invite him.

However, this does not seem to be the case, as we will see in section 3.2. Many speakers accept sentence (37) as grammatical. We will need, then, more research as NI, in this respect, does not behave exactly like other RTs, as VP Preposing, Top, Adverb Dislocation, Right Dislocation, etc.

\subsection{Only Inversion}

As we have seen in the introduction, Only inversion is considered, for some authors, an instance of NI, and, as a result, has not been analysed in isolation (1.e).

(1.e) Only then did he realize that he had made a terrible mistake (Francis 2017: 214). 
Jacobsson (2007), amongst other authors as Haegeman (2000), for instance, considers Only inversion as preposed negative element in NI. However, if Only Inversion was an occurrence of NI, we would expect them to behave alike. Nevertheless, there are some differences between them.

The first difference is that, unlike NI, Only is not monotone decreasing (38), a requirement to be treated as NI (Collins and Postal: 2014). Because (38.a) does not entail (38.b), i.e. saying that Only Nancy eats vegetables (38.a), Only Nancy eats spinach (38.b) does not have to be the case. In contrast with (39), where On no account should you eat a piece of fruit for breakfast (39.a) entails On no account should you eat an apple for breakfast (39.b).

(38) a. Only Nancy eats vegetables.

b. Only Nancy eats spinach (Collins and Postal 2014: 134).

(39) a. On no account should you eat a piece of fruit for breakfast.

b. On no account should you eat an apple for breakfast (Haegeman 2000: 32).

Another difference between Only inversion and NI is that in NI, inversion is obligatory in most cases (4) -repeated below-, whereas in Only inversion, as it can be deduced by Collins and Postal (2014: 134)'s claim that "all speakers allow Negative Inversion with only phrases", non-inversion is also acceptable (56).

(4) a. I have never seen such a big lion.

b. Never have I seen such a big lion.

c. *Never I have seen such a big lion.

(40) a. Only on Fridays do I go out with my cousin.

b. Only on Fridays I go out with my cousin.

In section 3.3. I will give evidence for the optionality of inversion in Only preposed sentences. Although it is true that both inverted and non-inverted sentences are grammatical, most speakers do not accept both as grammatical, i.e. some speakers seem to like the inverted sentence more than the non-inverted counterpart, and vice versa.

\section{EXPERIMENT AND RESULTS}

A series of issues were previously considered which are a topic of debate when describing the Negative Inversion phenomenon. As we have seen above, for most issues there is not a consolidated agreement amongst authors, which means that there are no consistent results in the literature about the grammaticality judgements of some of these issues.

A new experiment was conducted to verify the claims made by some authors. For this, I created an online survey in Google Forms and added the sentences which I wanted 
confirmation to verify their grammaticality. I divided the poll into 5 sections: section 1 was a control question, section 2 contained negative preposed elements which were both adjuncts and complements, as to account for the optionality of inversion in NI, section 3 featured if clauses, because clauses and complex NPs, and the last section was about optionality of inversion in Only Inversion sentences.

Amongst the 84 subjects who filled the survey, only 14 (17\%) were selected to trust their grammaticality judgements on NI sentences in the rest of the sections with the exception of the last section (Only inversion). I only took into account those speakers who were well behaved taking into account what we know in the literature, i.e. people who accepted both (41.a) and (41.b) as equally grammatical sentences and rejected (41.c) at the same time, which meant they were productive users of NI (the $17 \%$ mentioned). This is because, as the survey was online, more control was needed, as there were variables which could not be accounted for.

(41) a. I would never eat spinach.

b. Never would I eat spinach.

c. *Never I would eat spinach.

\subsection{Optionality of Inversion}

As I have previously stated above in section 3.1., there is not an agreement on what the role of inversion is in preposing of negative elements. Haegeman (2000) states that inversion is always compulsory, and instances of non-inversion are cases of ellipsis; Cormark and Smith (2000) consider inversion and non-inversion to be equally acceptable; and Büring (2004) claims that NI can occur with both adjuncts and complements, although inversion with complements is rare, so, as a result, the non-inverted counterpart is more used in this case.

To check which of these is the more accurate approach, I decided to provide six sentences (42) in the survey: four sentences featuring subject-auxiliary inversion (42 a-d) and two sentences without inversion (42 e-f). Out of the first four sentences, the first two (42 a-b) are examples of preposed negative adjuncts and the last four (42 c-f) are preposed negative complements, with (42 c-d) and without inversion (42 e-f).

(42) a. On no account could she move to Paris (adjunct) (De Clercq 2010: 1).

b. Not until December can we go to see grandma (adjunct).

c. Not a sound could we hear (complement) (Google).

d. None of those would he want to eat (complement) (Büring 2004: 1).

e. Nothing I have seen that could rival the pyramids (complement no inversion) (Haegeman 2000: 26, footnote 5).

f. None of them he found useful (complement no inversion) (Büring 2004: 1). 


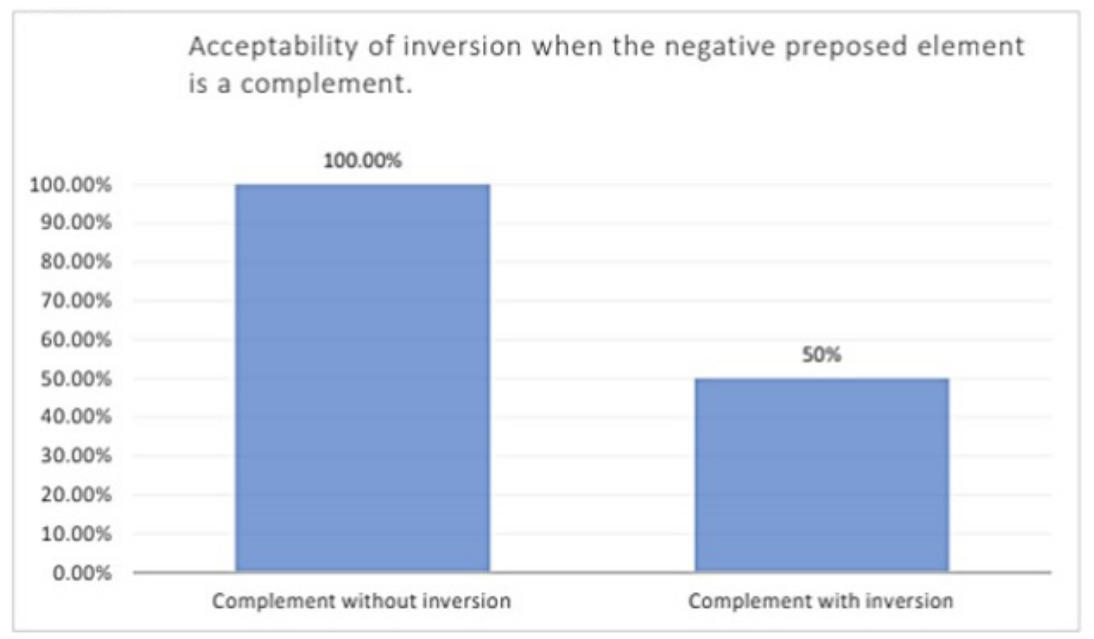

Table 1 . Acceptability of inversion when the negative preposed element is a complement

In table 1 we can see how preposed negative complements without inversion (42 e-f) are accepted by all the informants, whereas preposed negative complements with inversion were accepted by only $50 \%$ of them.

Then, table 1 shows Haegeman (2000)'s claim would not be appropriate, as not every non-inverted sentence can be explained by ellipsis, and neither would Cormark and Smith (2000)'s, because we can see that the inverted and the non-inverted counterpart are not equally acceptable. However, this table corroborates Büring (2004)'s claim that instances of subject-auxiliary inversion with preposed negative complements are rare, as $100 \%$ of the participants accepted the non-inverted sentences (42 e-f), whereas only $50 \%$ found negative preposed complements with inversion $(42 \mathrm{c}-\mathrm{d})$ grammatical.

Further research would be needed as to explain why and how this variation between preposed negative complements with and without inversion occurs.

\subsection{NI as a Root Phenomenon}

As it has been discussed before, Emonds (1964) and Hooper and Thomson (1973) consider NI a Root Phenomenon. However, I wanted to check four contexts to see if such claim was accurate or not. For this, I have divided this section into three subsections, marked by colours in Table 2: in blue, sentence (43.a) deals with if sentences; in green, sentence (43.b) deals with complex NPs; and in orange sentences (43.c) and (43.e) deal with two different because sentences.

The sentences used were:

(43) a. *If under no conditions may they leave the area, how can they pay their debt (Emonds 1964: 15). 
b. *The fact that never has he had to borrow money makes him very proud (Authier 1992: 332).

c. Gary is going to order chile relleno, because never in his life has he had a chance to try Mexican food (Hooper and Thompson 1973: 493).

d. *Mildred loves her husband (even) though seldom does he bring her flowers (Hooper and Thompson 1973: 494).

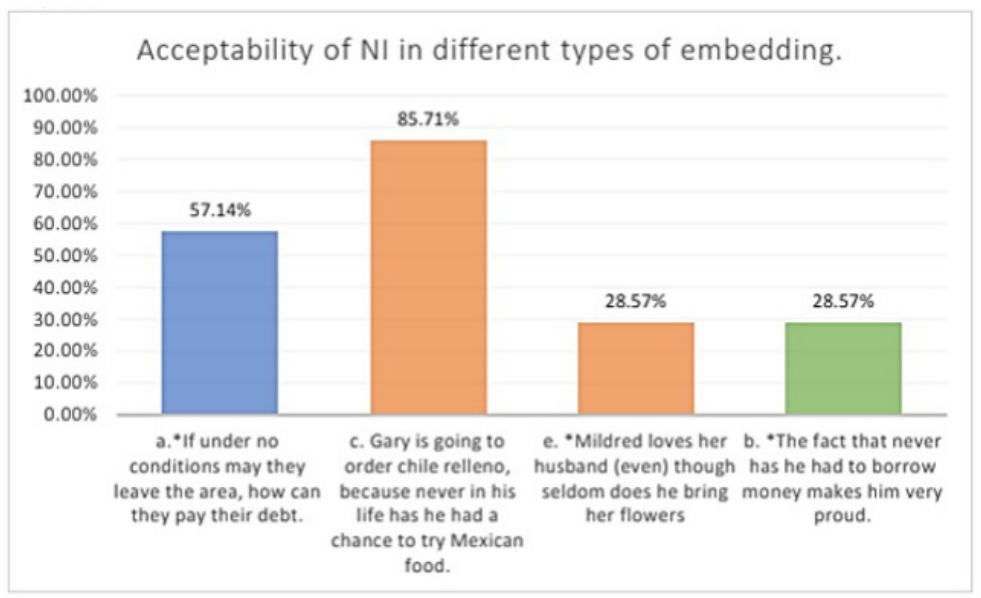

Table 2. Acceptability of NI in different types of embedding.

Let first consider sentence (43.b) which features NI in complex NPs. I have stated before that NI, as the rest of RTs, can appear as complements of embedded clauses introduced by Class A verbs as say, report, exclaim... but cannot appear within noun phrases (NPs) which have as their head a noun of saying. This is corroborated by the results in Table 2, as only $28.5 \%$ chose sentence (43.b) which features a complex NP which has as a head a verb of saying the fact that.

(43.b). * * The fact that never has he had to borrow money] makes him very proud (Authier 1992: 332).

From this fact we can conclude that, in general terms, this claim is correct, and NI does behave as other RTs in this respect. In what follows, I will consider the other two issues; because and if clauses.

In section 2.2. I stated that NI, as RTs, can appear in non-restrictive (NR) clauses, but cannot appear in restrictive clauses, as the former behave like root clauses but the latter does not. In this subsection I will consider an exception: we can see that NI can appear in both non-restrictive (44.a) and restrictive because clauses (44.b).

(44) a. Under no circumstances will Herbert be at this party, because I talked to his mother this morning (NR because clause). 
b. Never in his life had Sam gone out for dinner because his wife was cooking Japanese food (Restrictive because clause).

Hooper and Thomson (1973) point out that restrictive because clauses featuring NI only apply if they are presupposed (43 c-d) -repeated below-.

(43) c. Gary is going to order chile relleno, because never in his life has he had a chance to try Mexican food (Hooper and Thompson 1973: 493) (Presupposed).

d. *Mildred loves her husband (even) though seldom does he bring her flowers (Hooper and Thompson 1973, 494) (Not presupposed).

Table 2 gives evidence for this fact, as $85.7 \%$ of the participants chose (43.c) as grammatical, whereas only $28.5 \%$ of them liked (43.e). Then, we can see that NI does not strictly behave as other RTs, as it actually can appear in presupposed restrictive because clauses. In the next subsection, when considering if clauses, we will find more evidence of NI not behaving precisely like other RTs as Topicalization, for instance.

As we have seen here, NI is supposed to behave like other RTs, and, for the most part, it does. However, presupposed restrictive because clauses and preposed if clauses featuring NI are problematic for this assumption. At the end of section 2.2. I argued that NI sentences are expected to behave as Topicalization in if sentences, i.e. they should be ungrammatical, as Emonds (1964) proposes.

However, I have found a counterexample (43.a) -repeated blow- to this statement of Emond (1964)'s, as the results of the questionnaire I have conducted shown in Table 2. contradict this assumption: $57.15 \%$ of the informants, more than half of them, accepted the if sentence as grammatical.

(43.a) If under no conditions may they leave the area, how can they pay their debt (Emonds 1964: 15).

We can see, then, that NI does not follow all the requirements which are necessary for it to be considered a RT following the conditions provided by Emonds (1964) and Hooper and Thomson (1973), as it violates the requisite that it should not be able to appear in any embedded clause which does not behave as a root clause. Therefore, more research would be needed in order to give a full explanation for this fact.

\subsection{Optionality of Inversion in Only Inversion}

As I have mentioned before, unlike in NI sentences, subject-aux inversion in preposed Only sentences is believed to be optional (40) -repeated below-.

(40) a. Only on Fridays do I go out with my cousin.

b. Only on Fridays I go out with my cousin.

To check if this is the case, I added the sentences in (40) to the survey to see how native speakers behaved in this respect. 
In Table 3 we can see that most people preferred the inverted sentence, as $69 \%$ of the participants chose the subject-auxiliary inverted sentence when Only appeared preposed (40.a), whereas only $25.61 \%$ of them chose the non-inverted counterpart (40.b). In this respect, we can assume that most people treat Only inversion as NI.

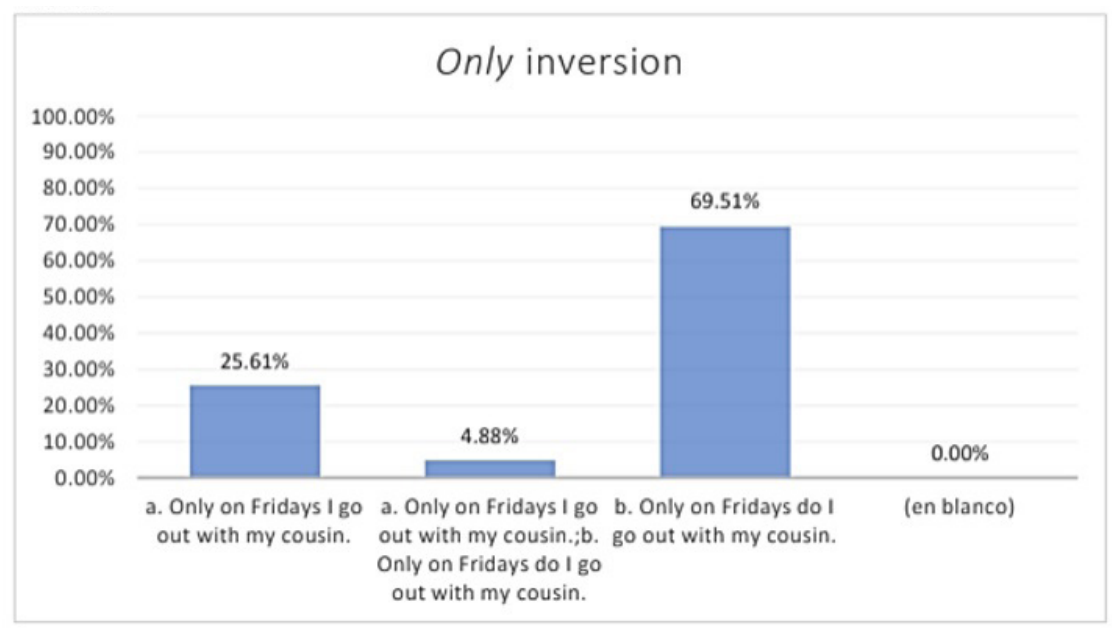

Table 3. Only inversion results

However, in descriptive English grammar books and webpages as Phil William's English Lessons Brighton (2018), BBC Learning English, Business English webpage, etc., the inverted order (40.a) is still preferred and advised, whereas the non-inverted sentence with a preposed Only (40.b) is not even mentioned.

It is also interesting to see that most speakers who chose (40.a) believed (40.b) to be wrong, and vice versa, and only $2.4 \%$ of the participants chose both (40.a) and (40.b) to be equally grammatical. These data show that there is cross-speaker variation (there are two options speakers choose from, some choose one, others choose the other) but not intra-speaker variation (each person chooses only one option, not both), which is not the case in NI either.

Then, with these results, one cannot conclude Only inversion and NI are the same phenomenon, as we saw in (4) -repeated below-, NI needs subject-auxiliary inversion (4.b), and a sentence without inversion is ungrammatical (4.c):

(4) a. I have never seen such a big lion.

b. Never have I seen such a big lion.

c. *Never I have seen such a big lion.

Further research is needed in this area as to be able to compare and distinguish between Only inversion and NI, even though, at first glance they look very much similar. 


\section{CONCLUSION}

This paper has analysed NI sentences, explaining their main, most important, characteristic which is that they trigger subject-auxiliary inversion in most cases. It has shown how NI is a unique phenomenon which cannot be compared to any other (whinversion, Top, FP or even Only inversion). It has given evidence for the fact that in Negative Preposing inversion can be optional sometimes, also explaining the distribution of this phenomenon within the sentence, i.e. in what environments we can and cannot use NI, concluding that NI should not be considered a RT. Furthermore, it has been argued that Only inversion should not be analysed as an instance of NI.

Further research is still needed to be able to give an explanation of NI within Universal Grammar and provide a general explanation of NI in all languages, and not only its case in English, as some authors like Jiménez-Fernández (2017) have stated the difficulty to apply the English analysis of NI to other languages such as Spanish.

\section{REFERENCES}

AuthiER, M. 1992. “Iterated CPs and Embedded Topicalization.” Linguistic Inquiry, 23(2): 329-336. http://www.jstor.org/stable/4178771.

BBC World Service. 2018. “Learning English”. BBC World Service. http://www.bbc. co.uk/worldservice/learningenglish/grammar/learnit/learnitv34shtml. Accessed May $17,2018$.

Branigan, P. 2005. The Phase Theoretic Basis for Subject-Aux Inversion. Canada: Memorial University.

BüRING, D. 2004. Negative Inversion. Pre-final draft. NELS. file://C:/Users/usuario/ AppData/Local/Temp/buring.negative.inversion.pdf.

Business ENGLISH. "Inversion". https:/www.businessenglish.com/grammar/inversion. html?lang=eng. Accessed May 17, 2018.

Collins, C. \& Postal, P. 2014. Classical NEG Raising an Essay on the Syntax of Negation. Linguistic Inquiry Monographs. Cambridge, Massachusetts/London, England: The MIT Press.

Cormack, A. \& Smith, N. 2000. "Fronting: The Syntax and Pragmatics of 'Focus' and 'Topic'.” UCL Working Papers in Linguistics, 12: 387-416.

Culicover, P. W. 2013. Explaining Syntax: Representations, Structures and Computation. Oxford: Oxford Linguistics.

De CLERCQ, K. 2010. NEG-shift in English: Evidence from PP-adjuncts. Ghent University/ GIST/ FWO-Odysseus Project.

Emonds, J. E. 1964. Root and Structure-Preserving Transformations. M.A: University of Kansas. 
Francis, N. 2017. "Modal Scope in Negative Inversion Constructions." In Proceedings of the 34th West Coast Conference on Formal Linguistics. Aaron Kaplan et al., eds. Somerville, M.A: Cascadilla Proceedings Project. 214-221.

Haegeman, L. 2000. "Negative Prepposing, Negative Inversion, and the Split CP." In Negation and polarity: syntactic and semantic perspectives. L. Horn and Y. Kato, eds. Oxford: Oxford. University Press. Pp. 21-61.

Haegeman, L. \& Guerón, J. 1999. English Grammar: A Generative Perspective. Oxford/ Malden, M.A: Wiley-Blackwell.

Hooper, J. B. \& Thomson, S A. 1973. "On the Applicability of Root Transformations." Linguistic Inquiry, 4(4): 465-497.

Horn, L R. 1996. "Exclusive Company: Only and the Dynamics of Vertical Inference." Journal of Semantics, 13. DOI: 10.1093/jos/13.1.1.

JACOBSSON, B. 1986. “Another Look at Negatively Conditioned Subject-Operator Inversion in English.” Studia Linguistica, 40(2): 161-185.

Jiménez-Fernández, Á. L. 2018. "Negative Preposing: Intervention and Parametric Variation in Complement Clauses." Atlantis, 40(1): 11-37.

Maekawa, T. 2007. Preposed Negative Expressions. The English Left Periphery in Linearisation-based HPSG. University of Essex. 155-197.

Radford, A. 2009. Analysing English Sentences, A Minimalist Approach. Cambridge University Press.

Sobin, N. 2003. "Negative inversion as nonmovement.” Syntax, 6: 183-212.

WiLliams, P. 2018. "How to start a sentence with 'only after / when / if"”. <http://www. englishlessonsbrighton.co.uk/only-after-inversion/> Accessed May 17, 2018. 